\title{
OCCUPATIONAL HAZARDS AND SAFETY MEASURES AMONG HEALTHCARE WORKERS IN A TERTIARY HEALTH INSTITUTION IN SOUTHERN NIGERIA
}

\author{
FRANCIS OSEMHOAHU ERAH ${ }^{1 *}$, EVERISTUS ANIAKU CHIJIOKE ${ }^{2}$, NOEL UWAIBI ${ }^{3}$, AKAMIEN J $^{1}$, \\ MARTIN OKHAWERE ${ }^{4}$
}

${ }^{1}$ Department of Community Medicine, Irrua Specialist Teaching Hospital, Irrua, Edo State, Nigeria. ${ }^{2}$ Public Health Operations Center, Nigeria Center for Disease Control, Abuja, Nigeria. ${ }^{3}$ Department of Community Medicine, Edo University, Iyamho, Edo State, Nigeria. ${ }^{4}$ Department of Clinical Sciences, Edo Specialist Hospital, Benin City, Edo State, Nigeria. Email: francozenith@yahoo.com

Received: 11 December 2013, Revised and Accepted: 09 April 2020

\section{ABSTRACT}

Objectives: The objectives of the study was to determine the occupational hazards HWCs face and the safety measure put in place to mitigate these hazards in a tertiary health institution in Edo State, Nigeria.

Methods: A cross-sectional descriptive study design was used to carry out this study among HWCs in a tertiary health institution. Data were analyzed with IBM-SPSS version 23 and statistical significance was set at $\mathrm{p}<0.05$.

Results: Out of the 163 respondents interviewed, $50.92 \%$ of them had poor knowledge of occupational hazard while $49.08 \%$ had good knowledge. All the doctors interviewed had good knowledge as compared to a larger proportion of other HWCs who had poor knowledge of occupational hazard and this association was statistically significant. Most of respondents (96.93\%) had positive attitude toward occupational hazard with few of them having poor safety measures to avoid injury in the work place.

Conclusion: Majority of Health care workers with the exception of medical doctors have poor knowledge of occupational hazards with poor safety measures though they may have positive attitude.

Keywords: Occupational hazards, Healthcare workers, Safety measures.

(C) 2020 The Authors. Published by Innovare Academic Sciences Pvt Ltd. This is an open access article under the CC BY license (http://creativecommons. org/licenses/by/4. 0/) DOI: http://dx.doi.org/10.22159/ijms.2020.v8i5.36598

\section{INTRODUCTION}

Worldwide, the health-care force represents $12 \%$ of the working population. Occupational hazards exist wherever healthcare is practiced [1,2]. There are numerous implications of occupational diseases and injury among health workers, which include: Physical, biological, chemical, ergonomics, and psychological damage to the worker and his family. Substantial morbidity and mortality among these workers inevitably lead to loss of skilled personnel and adversely impact health-care service, which are adversely strained in many low- and middle-income countries. To minimize these hazards in the workplace, health workers need to ensure hand hygiene, use of personal protective equipment, safe injection practices, safe handling of potentially contaminated equipment or surface in the patient environment, and respiratory hygiene. In addition, good knowledge of occupational hazards, proper, and effective compliance with safety measures will go a long way in addressing these hazards.

\section{METHODOLOGY}

A descriptive cross-sectional study design was utilized in this study involving HWCs in a tertiary institution. The sample size was determined using the Cochrane formula [3] for a descriptive cross-sectional study with a prevalence of occupational hazard in a previous study of $89 \%$, giving a minimum sample size of 163 after correcting for attrition. A stratified sampling technique with proportional allocation to size was used to select the health workers for the study. The questionnaire was used for data collection, which was entered into a spreadsheet and analyzed using the IBM-SPSS version 23.0. The results were presented in tables and charts where appropriate. Chi-squared test was used to test the association between variables and level of significance set at $\mathrm{p}<0.05$.

\section{RESULTS}

A total of 163 the socio-demographic characteristics of the respondents are shown in Table 1 . Most (41.7\%) of the respondents were within the age group 33-39 years. However, their ages ranged from 19 to 56 years, with a mean age of 36.31 , and a standard deviation of \pm 6.83 . About twothird $(62.6 \%)$ of the respondents were married. Females were more, making up $69.3 \%$ of the total number of respondents. The majority $(70.6 \%)$ of the respondents had a tertiary level of education, while 2 $(1.2 \%)$ and $4(27.1 \%)$ of the respondents had primary and secondary level of education respectively. Only $2(2.1 \%)$ of the respondents had no formal education. Most (96.3\%) were Christians and about twothird $(63.8 \%)$ were Esan. Nurses were more in this study, making up $35.6 \%$ of the total respondents. This was followed by doctors $(27.0 \%)$, cleaners (22.1\%), and laboratory scientist (14.7\%). Only one portal was interviewed. Respondents were drawn from the various departments of the hospital. Respondents from medicine and surgery departments were more as they made up $40.2 \%$, of the total number of HWCs interviewed. Pediatrics represented $19.6 \%$, obstetrics and gynecology $17.2 \%$, and hematology $15.3 \%$. Other departments (Accident and Emergency, Theater) made up $7.4 \%$. About two-fifth $(46.6 \%)$ of the respondents have worked for $<5$ years. However, the mean duration of employment was 7.7 years \pm 6.5 SD.

The respondents were fairly distributed in the department such as medicine (20.2\%), Surgery (20.2\%), Paediatrics (19.6\%), Obstetrics and gynaecology $(17.2 \%)$ and haematology $(15.3 \%)$ except theatre (2.5\%) and A and E (4.9\%) with mean duration of employment of $7.7 \pm 6.5$ years (Table 2). Knowledge of biological hazard were below $50 \%$. Needle stick injury (9.6\%), HIV/AIDS (49.1\%), Hepatitis (49.1\%), and Lassa fever (47.9\%) while knowledge in most other hazards 
Table 1: Socio-demographic characteristics of respondents

\begin{tabular}{|c|c|c|}
\hline Variable & Frequency $(n=163)$ & Percentage \\
\hline \multicolumn{3}{|l|}{ Age group (year) } \\
\hline$\leq 25$ & 8 & 4.9 \\
\hline $26-32$ & 39 & 23.9 \\
\hline $33-39$ & 68 & 41.7 \\
\hline $40-46$ & 37 & 22.7 \\
\hline $47-53$ & 9 & 5.5 \\
\hline$>53$ & 2 & 1.2 \\
\hline \multicolumn{3}{|l|}{ Mean $\pm S D=36.31 \pm 6.83$} \\
\hline \multicolumn{3}{|l|}{ Marital status } \\
\hline Single & 61 & 37.4 \\
\hline Married & 102 & 62.6 \\
\hline \multicolumn{3}{|l|}{ Sex } \\
\hline Male & 50 & 30.7 \\
\hline Female & 113 & 69.3 \\
\hline \multicolumn{3}{|l|}{ Level of education } \\
\hline No formal level of education & 2 & 1.2 \\
\hline Primary & 2 & 1.2 \\
\hline Secondary & 44 & 27.0 \\
\hline Tertiary & 115 & 70.6 \\
\hline \multicolumn{3}{|l|}{ Religion } \\
\hline Christianity & 157 & 96.3 \\
\hline Islam & 5 & 3.1 \\
\hline African traditional religion & 1 & 0.6 \\
\hline \multicolumn{3}{|l|}{ Tribe } \\
\hline Esan & 104 & 63.8 \\
\hline Etsako & 26 & 16.0 \\
\hline Bini & 12 & 7.4 \\
\hline Owan & 12 & 7.4 \\
\hline Others* & 9 & 5.4 \\
\hline \multicolumn{3}{|l|}{ Job category } \\
\hline Doctors & 44 & 27.0 \\
\hline Nurses & 58 & 35.6 \\
\hline Laboratory scientist & 24 & 14.7 \\
\hline Cleaners & 36 & 22.1 \\
\hline Potters & 1 & 0.6 \\
\hline
\end{tabular}

*Ibibio (1.8\%), Yoruba (1.8\%), Ibo (1.2\%), Tiv (0.6\%)

Table 2: Socio-demographic characteristics of respondents cont'd

\begin{tabular}{|c|c|c|}
\hline Ward/units & Frequency $(n=163)$ & Percentage \\
\hline Medicine & 33 & 20.2 \\
\hline Surgery & 33 & 20.2 \\
\hline Pediatrics & 32 & 19.6 \\
\hline Obstetrics and gynecology & 28 & 17.2 \\
\hline Hematology & 25 & 15.3 \\
\hline Others* & 12 & 7.4 \\
\hline \multicolumn{3}{|c|}{ Duration of employment (years) } \\
\hline$\leq 5$ & 76 & 46.6 \\
\hline $6-10$ & 49 & 30.1 \\
\hline $11-15$ & 16 & 9.8 \\
\hline $16-20$ & 12 & 7.4 \\
\hline $21-25$ & 7 & 4.3 \\
\hline$\geq 25$ & 3 & 1.8 \\
\hline \multicolumn{3}{|c|}{ Mean duration of employment $\pm \mathrm{SD}=7.70 \pm 6.50$} \\
\hline
\end{tabular}

*Theater (2.5\%), accident and emergency (4.9\%)

were above average (Table 3). All the resppondents with no formal education, $(100 \%)$ had poor knowledge of occupational hazard while a greater proportion of the respondents with tertiary level of education had good knowledge of occupational hazard but this association was not statistically significant. $\mathrm{p}=0.109$ (Table 4). All the doctors $(100 \%)$ had good knowledge of occupational hazard as compared to other healthcare workers and this association was found to be statistically significant. $p=0.000$ (Table 5). Fig. 1 showed the aggregate knowledge of occupational hazard among healthcare workers. $49.08 \%$ of the respondents had good knowledge while $50.92 \%$ had poor knowledge of occupational hazard. $96.9 \%$ of the respondents had positive attitude
Table 3: Knowledge of occupational hazards among healthcare workers

\begin{tabular}{|c|c|c|}
\hline Variables, n=163 & $\begin{array}{c}\text { Correct } \\
\text { response, } \mathrm{n}(\%)\end{array}$ & $\begin{array}{l}\text { Wrong } \\
\text { response, } \mathrm{n}(\%)\end{array}$ \\
\hline $\begin{array}{l}\text { Disease can be contacted from } \\
\text { patients }\end{array}$ & $163(100.0)$ & $0(0.0)$ \\
\hline $\begin{array}{l}\text { Infection occur by non- } \\
\text { observance of standard } \\
\text { precautions }\end{array}$ & $163(100.0)$ & $0(0.0)$ \\
\hline \multicolumn{3}{|l|}{ Occupational hazards } \\
\hline Physical hazards & $131(80.4)$ & $32(19.6)$ \\
\hline Biological hazards & $91(55.8)$ & $72(44.2)$ \\
\hline Chemical hazards & $100(61.3)$ & $63(38.7)$ \\
\hline Ergonomic hazards & $66(40.5)$ & $97(59.5)$ \\
\hline Psychosocial hazards & $93(57.1)$ & $70(42.9)$ \\
\hline \multicolumn{3}{|l|}{ Physical hazards } \\
\hline Cut & $44(88.3)$ & $19(11.7)$ \\
\hline Dust & $100(61.3)$ & $63(38.7)$ \\
\hline Smoke & $83(50.9)$ & $80(49.1)$ \\
\hline Noise & $77(47.2)$ & $86(52.8)$ \\
\hline \multicolumn{3}{|l|}{ Biological hazards } \\
\hline Needle stick injury & $32(9.6)$ & $131(80.4)$ \\
\hline HIV/AIDS & $80(49.1)$ & $83(50.9)$ \\
\hline Hepatitis B & $80(49.1)$ & $83(50.9)$ \\
\hline Lassa fever & $78(47.9)$ & $85(52.1)$ \\
\hline \multicolumn{3}{|l|}{ Chemical hazards } \\
\hline JIK & $92(56.4)$ & $71(43.6)$ \\
\hline Formaldehyde & $122(74.8)$ & $41(25.2)$ \\
\hline Dust & $151(92.6)$ & $12(7.4)$ \\
\hline \multicolumn{3}{|l|}{ Psychosocial hazards } \\
\hline Stress & $114(69.9)$ & $49(30.1)$ \\
\hline Verbal abuse & $102(62.6)$ & $61(37.4)$ \\
\hline Depression & $102(62.6)$ & $61(37.4)$ \\
\hline Lack of job satisfaction & $65(39.9)$ & $98(60.1)$ \\
\hline
\end{tabular}

Table 4: Knowledge and education of healthcare workers

\begin{tabular}{lccc}
\hline \multirow{2}{*}{ Level of education } & \multicolumn{2}{c}{ Knowledge of respondents } & \multirow{2}{*}{ Total (\%) } \\
\cline { 2 - 3 } & Poor (\%) & Good (\%) & \\
\hline No formal education & $2(100.0)$ & $0(0.0)$ & $2(100.0)$ \\
Primary & $1(50.0)$ & $1(50.0)$ & $2(100.0)$ \\
Secondary & $27(61.4)$ & $17(38.6)$ & $44(100.0)$ \\
Tertiary & $53(46.1)$ & $62(53.9)$ & $115(100.0)$ \\
Total & $83(50.9)$ & $80(49.1)$ & $163(100.0)$ \\
\hline
\end{tabular}

Fisher's $\mathrm{p}=0.109$

Table 5: Knowledge and job categories of healthcare workers

\begin{tabular}{lccc}
\hline Job category & \multicolumn{2}{c}{ Knowledge of respondents } & \multirow{2}{*}{ Total (\%) } \\
\cline { 2 - 3 } & Poor (\%) & Good (\%) & \\
\hline Doctors & $0(0)$ & $44(100)$ & $44(100)$ \\
Nurses & $39(67.2)$ & $19(32.8)$ & $58(100)$ \\
Laboratory scientist & $9(36.0)$ & $16(64.0)$ & $25(100)$ \\
Cleaners & $35(97.2)$ & $1(2.8)$ & $36(100)$ \\
Total & $83(50.9)$ & $80(49.1)$ & $163(100)$ \\
\hline
\end{tabular}

Fisher exact $\mathrm{p}<0.0001$

while $3.1 \%$ had negative attitude towards occupational hazards (Fig. 2). $93.3 \%$ of them had safety measures while $6.7 \%$ had poor safety measures (Fig. 3).

About half (49.08\%) of the respondents had good knowledge of occupational hazards among HCWs, while 50.9\% had poor knowledge of occupational hazards.

All of the respondents with no formal education (100\%) had poor knowledge of occupational hazards, and just about half of 


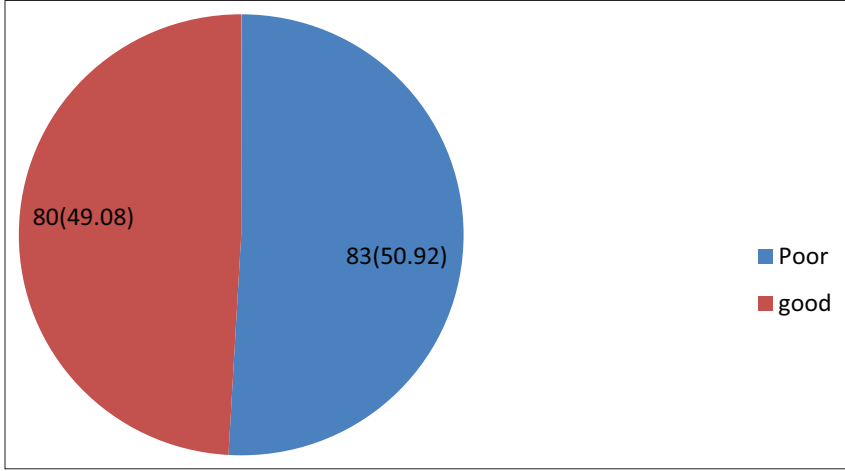

Fig. 1: Aggregate knowledge of occupational hazard among HCWs

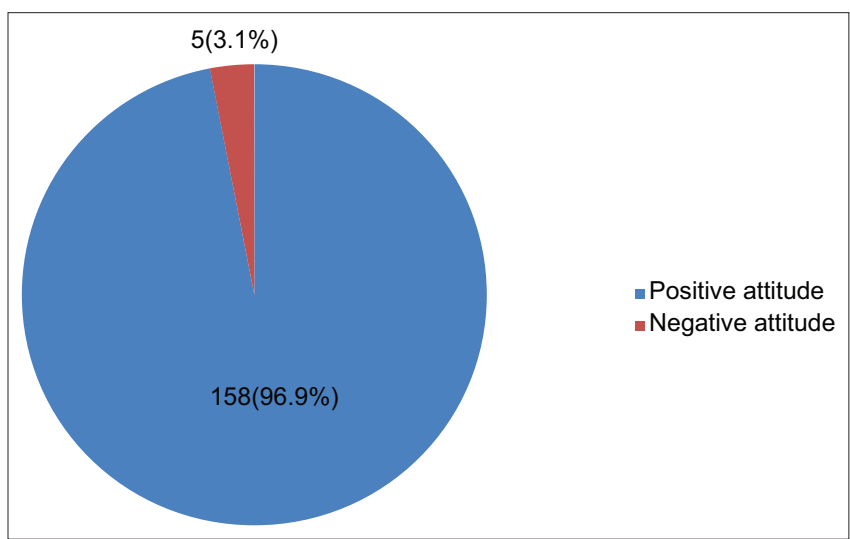

Fig. 2: Attitude of HCWs toward occupational hazards

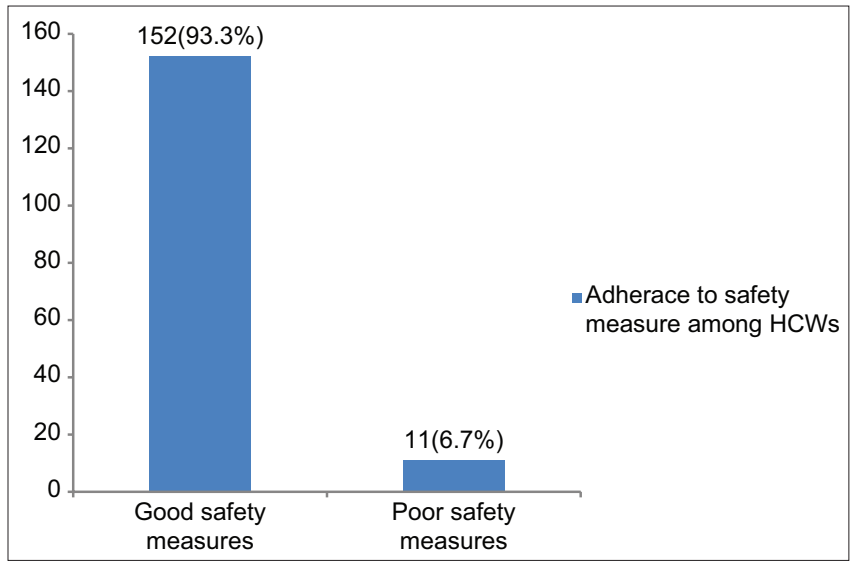

Fig. 3: Adherence to safety measure among HCWs

the respondents with tertiary education had good knowledge of occupational hazards (53.9\%) and this association was found not to be statistically significant $(\mathrm{p}=0.109)$.

All the doctors $(100 \%)$ had good knowledge, while a few of the cleaners $(2.8 \%)$ had good knowledge of occupational hazards and this association was found to be statistically significant. $\mathrm{p}<0.0001$.

Most of the respondents (96.9\%) had negative attitude toward occupational hazards, while a few of them had positive attitude toward occupational hazards.

Most of the respondents (93.3\%) had good safety measures, while few of them $(6.7 \%)$ had poor safety measures.

\section{DISCUSSION}

Findings from this study highlight that about half of the respondents had good knowledge of occupational hazards. This finding is similar to a study carried out in South-Eastern Ethiopia [1] and Uganda [4], where the knowledge of occupational hazards among HCWs was $53.7 \%$ and $50 \%$, respectively, but slightly different from a systematic study carried out in Africa which showed that about one-fifth of respondents had knowledge of occupational hazards [5]. This also contradicts a study done in the Philippines [4] where the majority $84.2 \%$ of respondents where knowledgeable about occupational hazard.

When a large proportion of HWCs do not have adequate knowledge of the occupational hazard, prevention of hazards with standard precaution is not likely, and this pose them to all manners of hazards. All of the respondents in this study understood that diseases can be contracted from patients and that infections occur by non-observance of standard precaution. Most of the respondents in this study had a positive attitude toward occupational hazards, and this is similar to a systematic study carried out in Africa where most of the respondents had a positive attitude toward occupational hazards [5]. This finding contradicts a study carried out in Iran [6] where of the 210 respondents, $75.5 \%$ of them had a positive attitude towards occupational health and safety.

Positive attitude toward occupational hazards sets a conducive atmosphere for workers in a hospital environment to observe standard precaution

In addition, more than half of the respondents in this study had experienced occupational hazards and this is similar to a study carried out in Uganda which showed that about half of participants in the study had experienced occupational hazards [7].

In this study, most of the respondents had good safety measures, while a few had poor safety measures. It is important for health care workers to have good safety measures in place to prevent hazards in the hospital work environment. The observance of standard precautions will ensure a healthy work environment as well as healthy workforce.

\section{CONCLUSION}

About half of the respondents in this study had good knowledge of occupational hazards, with most of them having a positive attitude toward occupational hazard, and most of them having good safety measures to prevent hazards in the workplace.

\section{REFERENCES}

1. Gulitat K, Tirumeh G. Assessment of knowledge, attitude and practices of healthcare workers on infection prevention in health institution. JPH 2014;2014:384-93

2. Eljedi A. Prevalence and response to occupational hazards among nursing students in Gaza strip Palestine: The role of personal protective equipment and safety regulations. Public Health Res 2016;5:32-8.

3. Cochrane G. Sampling Techniques. $2^{\text {nd }}$ ed. New York: John Wiley \& Sons, Inc.; 1977.

4. de Castro AB, Cabrera SI, Gee GC, Fujishiro K, Tagalog EA Occupational health and safety issues among nurses in Philippines. AAOHN J 2009;57:149-57.

5. Mossbug S, Agore A, Nkimbeny M, Commodore-Mensah Y. Occupational hazards among healthcare workers in Africa: A systematic review. Ann Global Health 2019;85:78.

6. Nasab HS, Ghafranipour F, Kazemnejad A, Khavanin A. Evaluation of knowledge, attitude and behavior of workers towards occupational health and safety. Iran J Public Health 2009;38:125-9.

7. Ndejjo R, Musinguzi G, Yu X, Buregyeya E, Musoke D, Wang J, et al. Occupational health among health care workers in Kampala Uganda. J Environ Public Health 2015;2015:913741. 